\title{
Preternatural Hexagonal High-Entropy Alloys: A Review
}

\author{
Rui-Xuan $\mathrm{Li}^{1}$ · Jun-Wei Qiao ${ }^{2} \cdot$ Peter K. Liaw ${ }^{3} \cdot$ Yong Zhang ${ }^{1}$ \\ Received: 27 December 2019 / Revised: 8 February 2020 / Published online: 10 April 2020 \\ (c) The Chinese Society for Metals (CSM) and Springer-Verlag GmbH Germany, part of Springer Nature 2020
}

\begin{abstract}
Recently, various topics on high-entropy alloys have been reported and great amounts of excellent properties have been investigated, including high strength, great corrosion resistance, great thermal stability, good fatigue and fracture properties, etc. Among all these research activities, high-entropy alloys tend to form face-centered-cubic (FCC) or body-centeredcubic (BCC) solid solutions due to their high-entropy stabilization effect, while the hexagonal structures are rarely reported. Up to now, the reported hexagonal high-entropy alloys are mainly composed of rare-earth elements and transitional elements. Their phase transformation and magnetic properties have also aroused wide concern. This study summarizes the above results and provides the forecast to the future.
\end{abstract}

Keywords High-entropy alloys $\cdot$ Hexagonal close-packed structure $\cdot$ Phase formation rules $\cdot$ Rare-earth elements Multiple-based-element (MBE) alloys

\section{Introduction}

High-entropy alloys (HEAs) have aroused wide public interests owing to their distinguished properties since they were first proposed in 2004 [1]. They usually consist of five or more components, and the atomic percentage of each component is $5-35 \%$ with no difference between the solute and solvent. As a result, different from the traditional alloys, the alloy-design range extends to the center of the phase diagram, and the large mixing entropy plays a dominant role to expand the dissolution range of the intermetallic compounds. Relatively, simple phase structures of face-centered cubic (FCC), body-centered cubic (BCC), or hexagonal close-packed (HCP) can be obtained. There are also some

Available online at http://link.springer.com/journal/40195.

Yong Zhang

drzhangy@ustb.edu.cn

1 Beijing Advanced Innovation Center of Materials Genome Engineering, State Key Laboratory for Advanced Metals and Materials, University of Science and Technology Beijing, 30 Xueyuan Road, Beijing 100083, China

2 Research Center for High-Entropy Alloys, College of Materials Science and Engineering, Taiyuan University of Technology, Taiyuan 030024, China

3 Department of Materials Science and Engineering, The University of Tennessee, Knoxville, TN 37996, USA
HEAs with amorphous structures [2, 3], but they are usually in the form of the film or small-sized sample, since the glassforming ability is low. Up to now, the vast majority of the published reports mainly concentrate on multi-phase alloys for their great comprehensive properties [4-6], or on the single-phase FCC or BCC structures for their high ductility or high strength, respectively. The FCC alloys, including $\mathrm{Al}_{0.3} \mathrm{CoCrFeNi}$ [7], CoCrFeNi [8], and CoCrFeMnNi [9], are mainly based on 3D transition metals and exhibit comparable plasticity. The BCC alloys, including AlCoCrFeNi [10], NbMoTaW [11], NbMoTaVW [12], WTaFeCrV [13], and HfNbTaTiZr [14], are mainly based on refractory metals, and show ultra-high strength. As for the HCP HEAs, however, much effort has been made but few achievements are reached.

The crystal structure of HCP metals is significantly different from that of FCC and BCC materials, which belongs to the simple hexagonal lattice and have two lattice constants $c$ and $a$. The metallic atoms are located not only at the junction of the hexagonal prism cell but also in the middle of the unit cell (at a height of $c / 2$ ). The projection of the central three atoms on the bottom surface is located at the center of gravity of three non-adjacent triangles. In an ideal close-packed structure, adjacent atoms on the (0001) plane are tangent, and the nearest neighbor atoms on the adjacent two (0001) planes are also tangent to each other, so the coordination number is 12 in a HCP unit cell. But in fact, many of the 
actual HCP metals are only closely packed, and the degree of atomic closeness on each crystal plane changes with the change of the axial ratio $c / a$. When $c / a>1.63$, only atoms in the same (0001) layer are tangent, while those on the adjacent (0001) planes are not tangent, and when $c / a<1.63$, it turns to the contrary. The ideal hexagonal close-packed structure is shown in Fig. 1a.

From the definition of high-entropy alloys, scientists have tried their best to prepare alloys with HCP structure. Chen et al. [15] tried to prepare $\mathrm{BeCoMgTi}$ and $\mathrm{BeCoMgTiZn}$, which are entirely composed of HCP elements, using mechanical alloying. Nevertheless, no crystalline solid solutions and compounds formed during milling except that an amorphous phase developed gradually until full amorphization was attained. Then, in 2013, Gao and Alman [16] predicted that the CoOsReRu alloy may form a HCP structure based on available binary/ternary phase diagrams and other simulations, while there are no experimental results proving. Equi-atomic YGdTbDyLu and GdTbDyTmLu alloys with single-phase HCP structures were put forward for the first time by Takeuchi et al. [17], followed by another kind of HCPHEA, HoDyYGdTb, reported in 2015 [18]. Since then, the HEAs have ushered a new era in that all possible metallic structures have emerged, including HEAs with BCC, FCC, $\mathrm{HCP}$, and amorphous structures. Since the size of different elements in HEAs can be very different in some cases (as shown in Fig. 1b), some differences on processing, properties, and deformation mechanisms have been made. In this study, HEAs with single-phase HCP structures and multiphase containing HCP structures are summarized, as well as their special properties and deformation mechanisms.

\section{Phase-Formation Rules}

\subsection{Empirical Criterions}

The Hume-Rothery criterion is an important theoretical basis in the physical metallurgy, which describes the effects of atom size, crystal structure, valence electron concentration, and electronegativity on the phase formation. Zhang et al. [19, 20] extended the "Hume-Rothery Criterion" to the field of HEAs after surveying a wide range of alloy compositions, which put forward that it is the difference in the atomic radius $(\delta)$, mixing enthalpy $\left(\Delta H_{\text {mix }}\right)$, and mixing entropy $\left(\Delta S_{\text {mix }}\right)$ that affects the phase formation of HEAs. In their criterion, the three main factors are defined as:

$\delta=100 \sqrt{\sum_{i=1}^{n} c_{i}\left(1-r_{i} / \bar{r}\right)^{2}}$,

where $\bar{r}=\sum_{i=1}^{n} c_{i} r_{i}, c_{i}$ and $r_{i}$ are the atomic ratio and atomic radius of the $i$ th component, respectively.

$\Delta H_{\text {mix }}=\sum_{i=1, i \neq j}^{n} c_{i} c_{j} \Omega_{i j}$,

where $\Omega_{i j}=4 \Delta H_{\text {mix }}^{\mathrm{AB}}$, and $\Delta H_{\text {mix }}^{\mathrm{AB}}$ is the mixing enthalpy of the binary alloy consisting of the $i$ th and $j$ th components in a regular solution, which can be calculated by the Miedema model [21]. $c_{i}$ and $c_{j}$ are the atomic ratio of the $i$ th and $j$ th components.
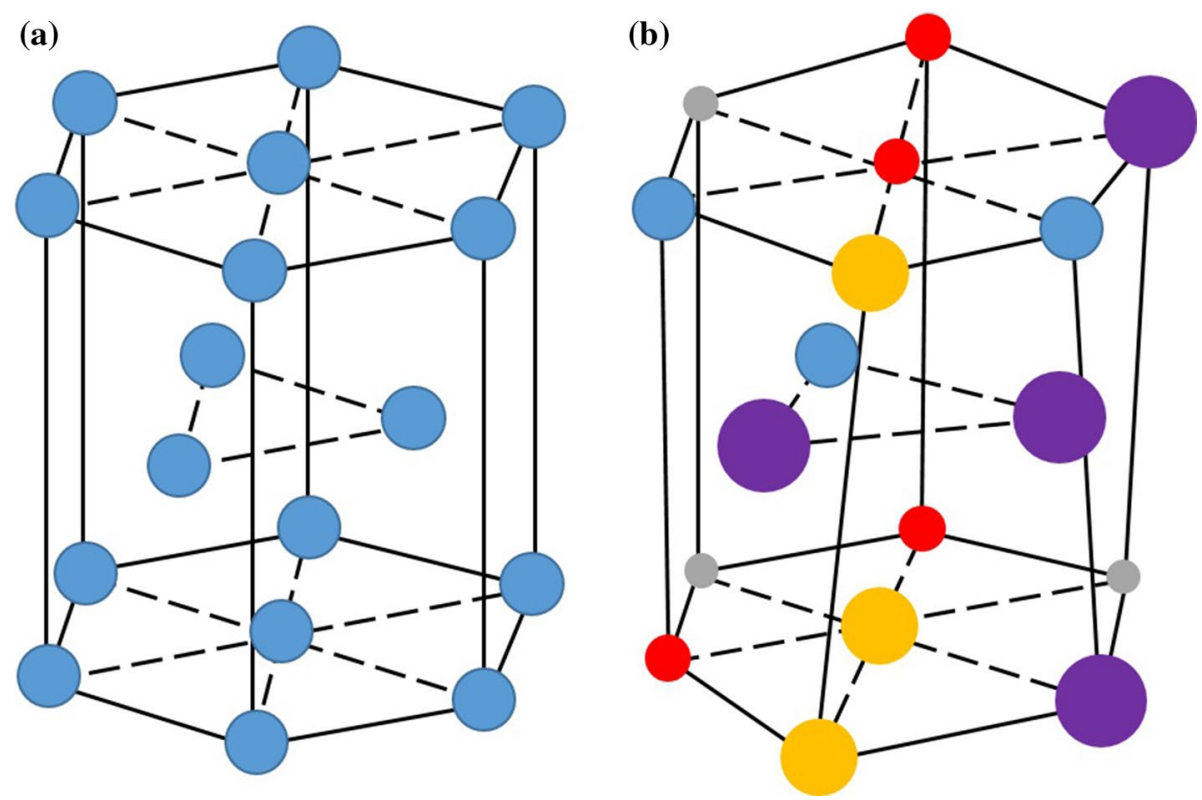

Fig. 1 a Ideal, b practical HCP structures in HEAs 
$\Delta S_{\text {mix }}=-R \sum_{i=1}^{n} c_{i} \ln c_{i}$,

where $R$ is constant.

After statistically calculating and analyzing, Zhang et al. [19, 22] plotted the relationship between the atomic radius difference and mixing enthalpy, as shown in Fig. 2. The range of the solid solution phase formation is the atomic radius difference is less than $6.5 \%$, and the mixing enthalpy is between $-15 \mathrm{~kJ} / \mathrm{mol}$ and $5 \mathrm{~kJ} / \mathrm{mol}$, just as the $\mathrm{S}$ and $\mathrm{S}^{\prime}$ areas in the figure. The areas where the bulk amorphous structure forms are present in B1 and B2 regions. A large negative enthalpy of formation causes the formation of intermetallics, while a positive enthalpy often results in the phase separation into terminal phases with low mutual solubilities.

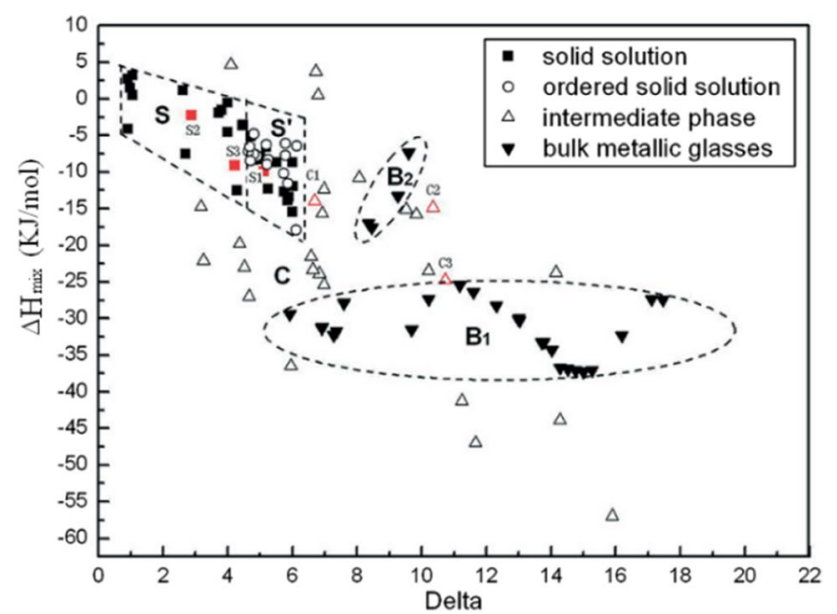

Fig. 2 Relationship between the atomic radius difference and the mixing enthalpy of the as-cast multi-component alloy [19]
Guo et al. [23] studied the relationship between the valence electron concentration (VEC) and the stability of the solid solution on the basis of Zhang et al. The VEC of the alloy is defined as:

$\mathrm{VEC}=\sum_{i=1}^{n} c_{i} \mathrm{VEC}_{i}$,

where (VEC) ${ }_{i}$ is the valence electron concentration of the $i$ th component. It is evident that the VEC has close relationship with crystal structure of HEAs. Ye et al. [24]calculated 90 cast HEAs and put forward that in the solid solution forming area, when $\mathrm{VEC}=8.5$, the FCC solid-solution phase is stable, while when VEC $=5$, the $\mathrm{BCC}$ solid solution phase is relatively stable, as shown in Fig. 3. The formation of a HCP structure falls in the region of $\mathrm{VEC}=2.8 \pm 0.2$. In this figure, $\Phi$ is another phase formation parameter put forward by $\mathrm{Ye}$ when the actual atomic size and actual degree of closeness are considered [25, 26], which is defined as

$\phi=\frac{S_{\mathrm{c}}-S_{\mathrm{H}}}{\left|S_{\mathrm{E}}\right|}$

where $S_{\mathrm{C}}$ denotes the configurational entropy of mixing for an ideal gas, $S_{\mathrm{E}}$ is the excessive entropy of mixing that is a function of atomic packing and atom size, and $S_{\mathrm{H}}$ is the complementary entropy derived from the enthalpy. There is a critical value $\Phi_{c} \sim 20$ that can effectively separate the single-phase solid solution from the multi-phase structure, after a lot of computing from five-, six-, seven-, and eightelement alloys with single- or multi-phased structures. An HEA tends to display a single-phase solid solution when $\Phi>\Phi_{\text {c. }}$

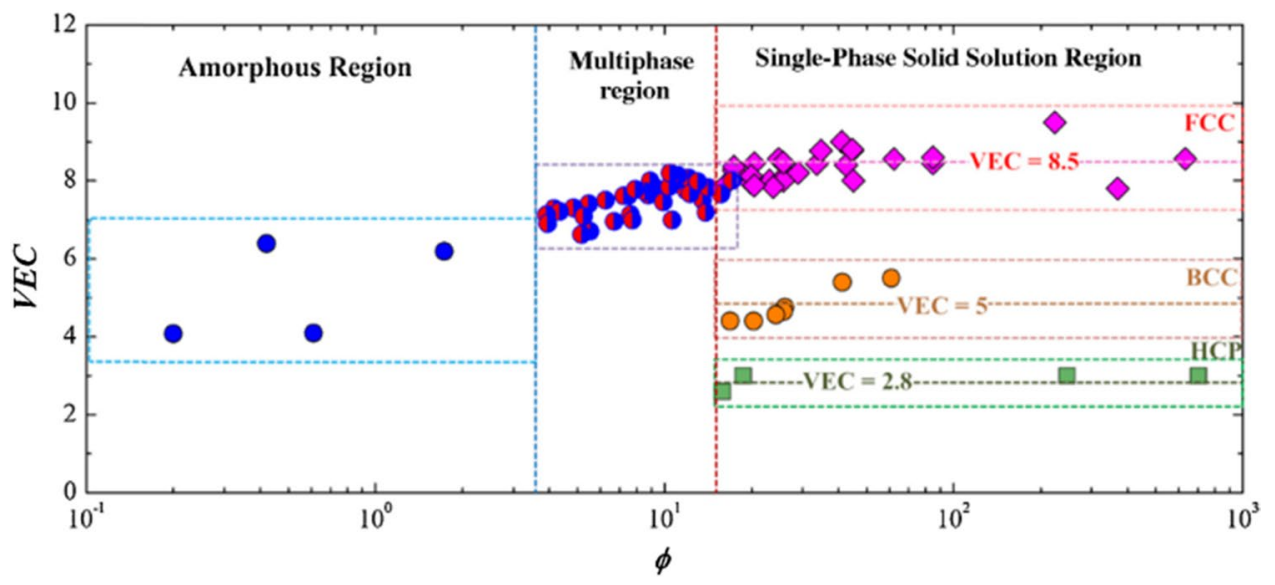

Fig. 3 Map of VEC and $\phi$ for different high-entropy alloys [24] 


\subsection{Calculations and Simulations}

The empirical rules of Zhang, Guo, Ye et al. [22, 25, 27, 28], and other scientists have successfully predicted a large number phase structures of high-entropy alloys. However, the enthalpy values from the Miedema model are not rigorous and accurate enough, relative to those from density functional theory (DFT) and calculations of phase diagrams (CALPHAD) modeling. Secondly, the lack of scientific basis leads to many compositions that satisfy these empirical rules but form multi-phase structures instead. This phenomenon indicates the necessity of developing more restrictive criteria (e.g., at atomic level) for single-phase solid solution formation.

A more reliable approach to predict phase formation is proposed by Gao and Alman [16]. They use predictive ab initio molecular dynamics (AIMD) simulations to investigate the nature of interatomic interaction and the CALPHAD method for calculating multi-component phase diagrams. By combining the computational simulations with binary and ternary phase diagrams, a new single-phase HCP multicomponent solid solution $\mathrm{Co}-\mathrm{O}-\mathrm{Re}-\mathrm{Ru}$ was predicted. The binary phase diagrams show that there is no compounds formation in $\mathrm{Co}-\mathrm{Os}, \mathrm{Co}-\mathrm{Re}, \mathrm{Co}-\mathrm{Ru}$, Os-Re, Os-Ru, and $\mathrm{Re}-\mathrm{Ru}$ binaries at lower temperatures, and it indicates the formation of isomorphous HCP solid solution at room temperature. Also using this efficient searching strategy, Gao et al. [29] predicted a series of alloy compositions that hold significant potential in forming single-phase HCP HEAs, such as $\mathrm{CoCrReRu}, \mathrm{CoCrFeReRu}$, and CoPtReRu. There are also some other favorable rare earth elements, such as Sc, Y, Sm, Gd, Tb, Dy, Ho, Er, Tm, and Lu. It could be a total of 974 equi-molar alloys with four to ten principal components, although future experiments are still desired to verify these predictions. They conclude that the HCP HEAs can be prepared with a high probability when using (1) rare-earth elements; (2) double HCP elements; and (3) isomorphous transitional elements as main constituent elements.

\section{Constituent Elements}

\subsection{HCP HEAs with Rare-Earth Elements}

Zhang et al. [20] first proposed that it is likely to form HCP HEAs made up of rare-earth elements, because they have similar atomic sizes and crystal structures, and because they can form homogeneous solid solutions based on their binary phase diagrams. Based on this prediction, equi-atomic Y-Gd-Tb-Dy-Lu and Gd-Tb-Dy-Tm-Lu alloys with all the HCP rare-earth elements were designed and prepared in 2014 by Japanese scientists Takeuchi [17], which was assisted by the binary-phase diagrams and the elemental miscibility. These two kinds of HEAs are confirmed as an HCP structure by distinct sharp peaks in the X-ray diffraction (XRD) patterns. However, the enlarged XRD patterns contain some unknown phases, although the volume fractions of these unknown phases are negligibly smaller than the primary crystalline phases. The analysis of the XRD patterns also reveals that the XRD peaks are the reflections of the HCP structure with lattice constants of $a=0.364 \mathrm{~nm}$, $c=0.573 \mathrm{~nm}$, and $c / a=1.574$ for the $\mathrm{Y}-\mathrm{Gd}-\mathrm{Tb}-\mathrm{Dy}-\mathrm{Lu}$ alloy. Furthermore, it is found that they have the delta parameter $(\delta)$ values of 1.4 and 1.6, respectively, and mixing enthalpy $\left(\Delta H_{\text {mix }}\right)$ equal to $0 \mathrm{~kJ} / \mathrm{mol}$ for both, located in Zone $\mathrm{S}$ for disordered HEAs in a $\delta-\Delta H_{\text {mix }}$ diagram reported by Zhang et al., as shown in Fig. 3, which in turn proves the accuracy of the Zhang's criterion.

Thereafter, Feuerbacheret al. [18] prepared the Ho-Dy-Y-Gd-Tb HEA through arc melting, and nanoscale samples were taken using a focused ion beam (FIB) from the centers of the ingots. The scanning electron microscopy, electron diffraction investigations, and high-resolution scanning transmission electron microscopy are employed, implying that this kind of alloy exhibits the HCP structure. The material is found to be homogeneous macroscopically and microscopically; no features due to composition variation, precipitation of secondary phases, dendrite formation, etc., could be observed by transmission electron microscopy (TEM). The electron diffraction pattern is inconsistency with an Mg-type structure and displays perfect hexagonal symmetry. Later, as a complementary result, Luzniket al. [30] proved the HCP structure of this Ho-Dy-Y-Gd-Tb HEA using XRD pattern, which also demonstrate that all peaks could be indexed to an HCP structure (space group $\mathrm{P} 63 / \mathrm{mmc}$ ) with the lattice parameters $a=0.3613(1) \mathrm{nm}$ and $c=0.5704(2) \mathrm{nm}$.

Almost simultaneously, the group of Qiao successfully prepared several pure rare earth HCP alloys without any second phase, and firstly revealed their mechanical properties and the role of solid solution strengthening effect in it [31]. Details will be discussed in the next section.

\subsection{HCP HEAs with Transitional Elements}

Although HCP structure can be successfully prepared using rare-earth elements, the cost of them is relatively high, and the rare-earth alloys usually have poor mechanical properties. The HCP HEA with transitional elements Ir-Os-Re-Rh-Ru was firstly developed through a special chemical method, that is, the thermal decomposition of a single-source precursor [32]. It was found that the $\mathrm{Ir}_{0.19} \mathrm{Os}_{0.22} \mathrm{Re}_{0.21} \mathrm{Rh}_{0.20} \mathrm{Ru}_{0.19}$ alloy maintained the structural stability with no phase change at temperatures up to $1200^{\circ} \mathrm{C}$ and isostatic pressures up to $45 \mathrm{GPa}$, which proves that it has 
great high-temperature stability and has the potential to be used as superalloys.

Takeuchi et al. [33] prepared a senary ScYLaTiZrHf HEA with a novel double HCP structure. The scanning electron micrograph of ScYLaTiZrHf and the distribution map of each element show that in this dual structure, one is mainly composed of $\mathrm{Y}$ and $\mathrm{La}$, and another is mainly $\mathrm{Ti}, \mathrm{Zr}$, and Hf. This is because of the evolution of dendrites and the difference in interatomic forces. The mixing enthalpy of $\mathrm{Y}-\mathrm{La}, \mathrm{Ti}-\mathrm{Zr}$, Ti-Hf, and $\mathrm{Zr}-\mathrm{Hf}$ are all equal to 0 , while that of other elemental pairs is larger than $10 \mathrm{~kJ} / \mathrm{mol}$. The slightly large enthalpy of Sc-(Y, La, Ti, Zr, Hf) contributes to the homogeneous distribution of Sc. Further calculation indicates that this is not an entropy-driven alloy with mixing enthalpy $\Delta H_{\text {mix }}=11.4 \mathrm{~kJ} / \mathrm{mol}$. A new design strategy to alloys with double or three phases may be provided in this work, by using significantly different mixing enthalpy of elements.

Furthermore, HEAs made up of 3D transition elements can also exhibit HCP structures. In 2016, Tracy et al. and Zhang et al. [34, 35] almost simultaneously found that the CoCrFeMnNi HEA can be transformed from FCC to HCP structures under high pressure, and the alloy maintained the $\mathrm{HCP}$ structure after reducing the pressure. Their results are shown in Figs. 4 and 5, respectively. In Fig. 4, the CoCrFeMnNi alloy is prepared by arc melting. The alloy exhibits single FCC phase at $14 \mathrm{GPa}$, and almost all convert to the HCP phase at 54.1 GPa, while in Fig. 5, gas atomization is used, and the alloys are all FCC phase at $19.5 \mathrm{GPa}$. Then, almost all of them convert to the HCP phase when the pressure increases to $41 \mathrm{GPa}$. The difference in the critical value of the phase transition may be due to the difference in the preparation method. Both Tracy and Zhang believe that it is the lower stacking fault energy of the HCP structure under high pressures that cause this phenomenon. In addition to the ultra-high pressure, the phase transformation from FCC to HCP structures in $\mathrm{CoCr}-$ FeMnNi can also be induced by the cryogenic high-pressure torsion [36], and the HCP phase is proved to be stable at low temperatures by thermodynamic calculations.

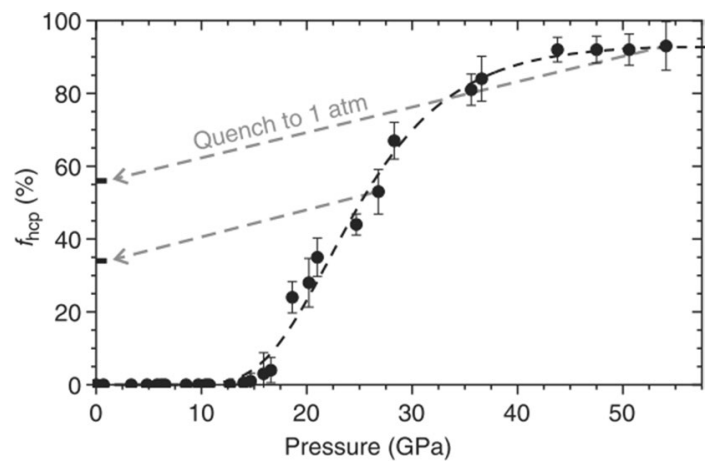

Fig. 4 HCP phase fraction as a function of pressure [28]
Another phase transformation from FCC to HCP happened in a novel low-density HEA $\mathrm{Al}_{20} \mathrm{Li}_{20} \mathrm{Mg}_{10} \mathrm{Sc}_{20} \mathrm{Ti}_{30}$ after annealing [37]. The material prepared by mechanical alloying was observed to have a single-phase FCC crystal structure in the as-milled condition initially. After annealing this sample at $500{ }^{\circ} \mathrm{C}$ for $1 \mathrm{~h}$, the crystal structure changed to hexagonal.

The hexagonal structure can also be inco-existence with the FCC structure. Li et al. [38] developed a transformationinduced plasticity-assisted dual-phase HEA Fe ${ }_{50} \mathrm{Mn}_{30} \mathrm{Cr}_{10} \mathrm{Co}_{10}$ with varying phase fractions. The fraction of the HCP phase changes along with the variation of the annealing time and deformation. It was investigated that the sample annealed for only $3 \mathrm{~min}$ at $900{ }^{\circ} \mathrm{C}$ is fully recrystallized with the HCP phase fraction of $\sim 32 \%$. Interestingly, the further increase in the annealing time to $60 \mathrm{~min}$ results in the HCP phase fraction dropping to $\sim 14 \%$ firstly, and then linearly increasing to $36 \%$. Another influence factor is the local strain level. The fraction of HCP phase maintains increasing with the increase in strain level. With increase in local strain from 0 to $10 \%$ and further increase to $30 \%$, the average fraction of the HCP phase obtained from EBSD increases from 28 to $46 \%$ and further increase to $70 \%$. Finally, with further increase in strain to $65 \%$, localized necking occurs and still approximately $80 \% \mathrm{HCP}$ phase is retained.

There are also some other kinds of phases coexisting with the HCP structure in the alloy, and these HCP phases usually present among dendrites slightly. Tsau and Chang [39] found that there are HCP phase existing in the dendrites of the BCC phase in the quaternary alloy $\mathrm{TiCrZrNb}$ of film state. He also found hard ordered HCP dendrites in the ascast TiFeCoNi alloy [40], which did not alter its HCP dendrite structure after annealing at $1000^{\circ} \mathrm{C}$. Shun et al. [41, 42] also reported the interdendritic $\mathrm{HCP}$ phase in $\mathrm{Al}_{0.3} \mathrm{CoCrFeNiTi}_{0.1}$ and $\mathrm{CoCrFeNiTi} i_{0.3}$.

\section{Properties}

\subsection{Mechanical Properties}

The group of Qiao et al. developed a variety of rare-earth HCP HEAs and deeply analyzed their mechanical properties. They reported the Gd-Ho-La-Tb-Y as a new HCP HEA system [31], and found that the hardness value of this alloy obey the rule of mixture, or the "additivity law," which can be expressed as

$p=\sum_{i=1}^{n} c_{i} p_{i}$

where $c_{i}$ and $p_{i}$ are the atomic percentage and the mechanical property of each constituent element, respectively. They also widely applied the mixing rules to the alloy's $c / a$, hardness, 


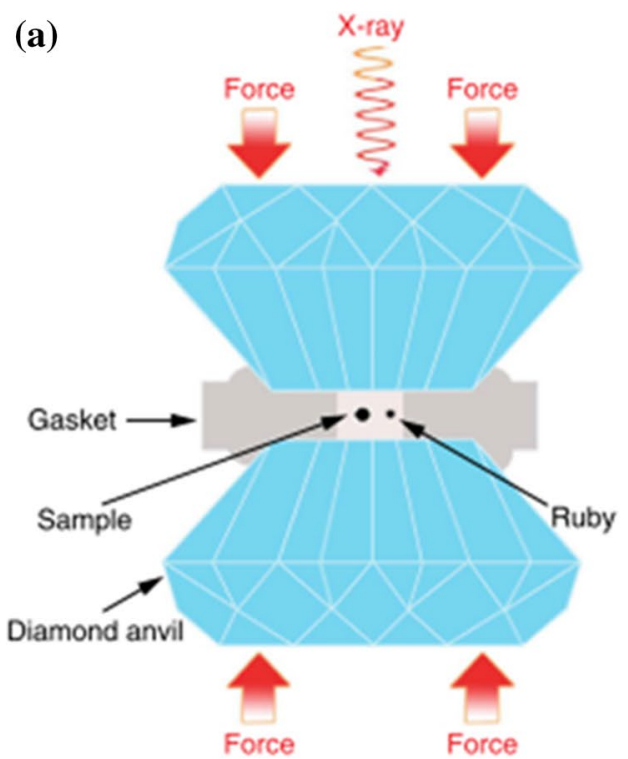

(b)
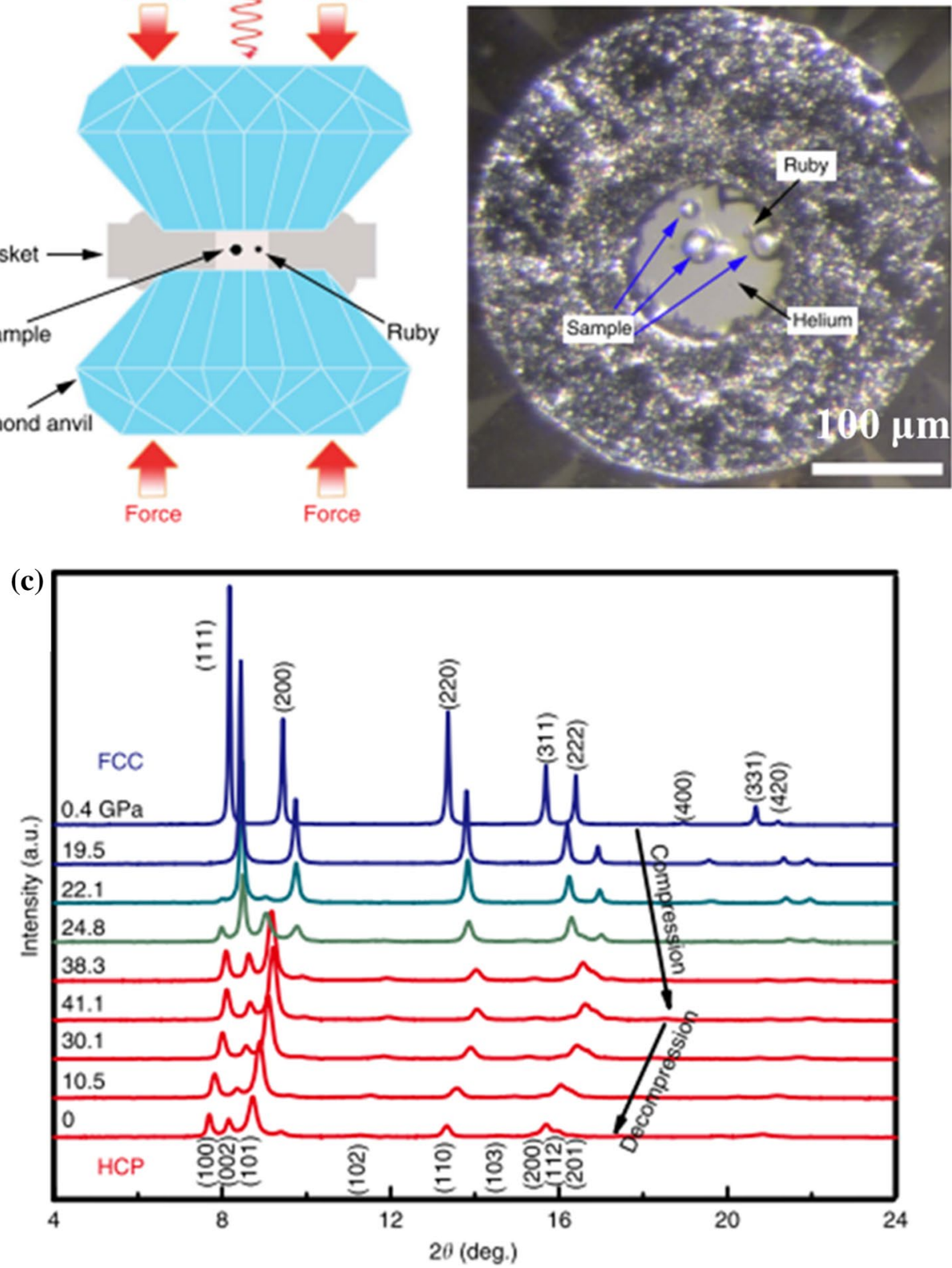

Fig. 5 a, b Experimental setup, c the in situ high-pressure XRD patterns of the CoCrFeMnNi HEA [29]

yield strength, fracture strength, plastic deformation, lattice constant, etc., and they were all found to be consistent with the mixing rule. On the contrary, as shown in Fig. 6, the measured Vickers hardness of FCC CoCrFeNi and BCC MoNbTaVW is significantly greater than the average hardness values calculated from the rule of mixture. This indicates that the high-entropy did not contribute to the same hardening effect in this kind of HCP HEA.

Then, this group also reported HCP HEAsDyErGdHoLuScTbY, DyGdHoLaTbY, and ErGdHoLaTbY [43].Their measured compressive yield stress values were 245, 205, and
$360 \mathrm{MPa}$, respectively, and the corresponding solid solution strengthening contributions were only estimated as 28,27 , and $42 \mathrm{MPa}$, respectively. Based on the fact that the solid solution strengthening of alloys is caused by the elastic interactions between the local stress fields of solute atoms and those of dislocations, the solid solution strengthening caused by element $i$ can be expressed as

$\Delta \sigma_{i}=Z G f_{i}^{4 / 3} c_{i}^{2 / 3}$ 


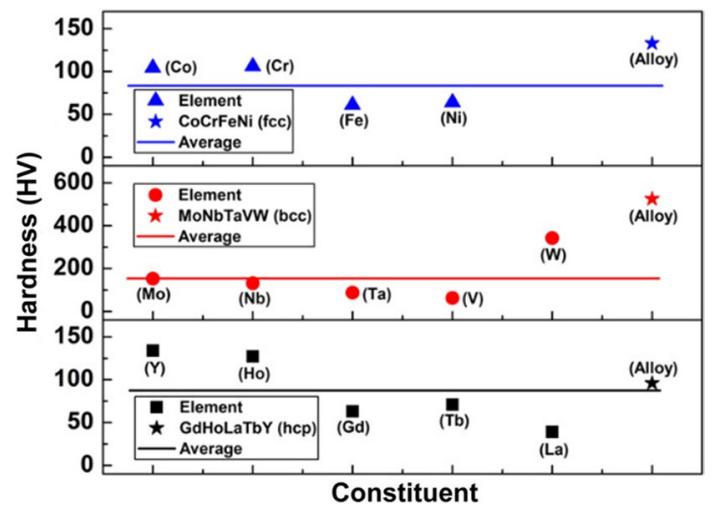

Fig. 6 Relationships of hardnesses for three kinds of HEAs, CoCr$\mathrm{FeNi}$, MoNbTaVW, and GdHoLaTbY, and their constituent elements [31]

where $Z$ is a material-dependent dimensionless constant, $G$ is the shear modulus of the alloy, $c_{i}$ is the concentration of element $i$, and $f_{i}$ is the mismatch parameter. The $f_{i}$ parameter can be calculated by

$f_{i}=\sqrt{\delta G_{i}^{2}+\alpha^{2} \delta r_{i}^{2}}$

where $\delta G_{i}$ is the atomic modulus mismatch parameter, $\delta r_{i}$ is the atomic size mismatch parameter, and $\alpha$ is a constant. By summing $\Delta \sigma_{i}$ of every component of the alloy, the solid solution strengthening $(\Delta \sigma)$ of the alloy is calculated by

$\Delta \sigma=\left(\sum \Delta \sigma_{i}^{3 / 2}\right)^{2 / 3}$.

Then, the total yield stress of the alloy is calculated by

$\sigma_{y}^{\mathrm{cal}}=\sigma_{y}^{\mathrm{mix}}+\Delta \sigma$,

where $\sigma_{y}^{\text {mix }}$ is the average of yield stress calculated using Eq. 6 .

The comparison in the yield stress between calculations and experiments, and the calculated solid solution strengthening value is exhibited in Fig. 7. It indicates that solid solution strengthening provides a lower proportion of total strength, which challenges the fundamental assertion that "solid solution strengthening is the most important strengthening mechanism for HEAs" and is instructive for the future study of the mechanical properties.

\subsection{Magnetic Properties}

At present, studies on the magnetic properties of HEAs mainly focus on the soft magnetic properties of alloys with FCC, BCC, or amorphous structures [44-48]. Soft magnetic materials are those which can easily magnetize and demagnetize under a relatively weak magnetic field, and high-entropy alloys have drawn much attention for their especially low coercivity and saturation magnetization. The entropy increasing and chemical disordered structure make the magnetic reordering more difficult than traditional magnetic compounds, which is expected to raise coercivity. And the equi-atomic composition naturally reduces the concentration of nonmagnetic elements, which therefore reduce the saturation magnetization of alloys.

On the other hands, the magnetocaloric effect of HEAs has also generated some concern, and this in turn focuses on the HCP HEAs. The magnetocaloric effect refers to the exothermic or endothermic phenomenon when the magnetic field is enhanced or weakened, or the entropic change or adiabatic heating caused by the magnetization or demagnetization. The orientation of the magnetic moment in a magnet is disordered without magnetic field. At this time, the magnetic entropy is larger and the adiabatic temperature is lower. When the magnetic field is applied, the magnetic moment tends to be parallel to the magnetic field, resulting in magnetic entropy decrease, adiabatic temperature rise, and heat release; while when the magnetic field becomes smaller, things are opposite and heat absorption happened. The magnetic entropy change is defined by magnetic field $H$ and temperature $T$ as:
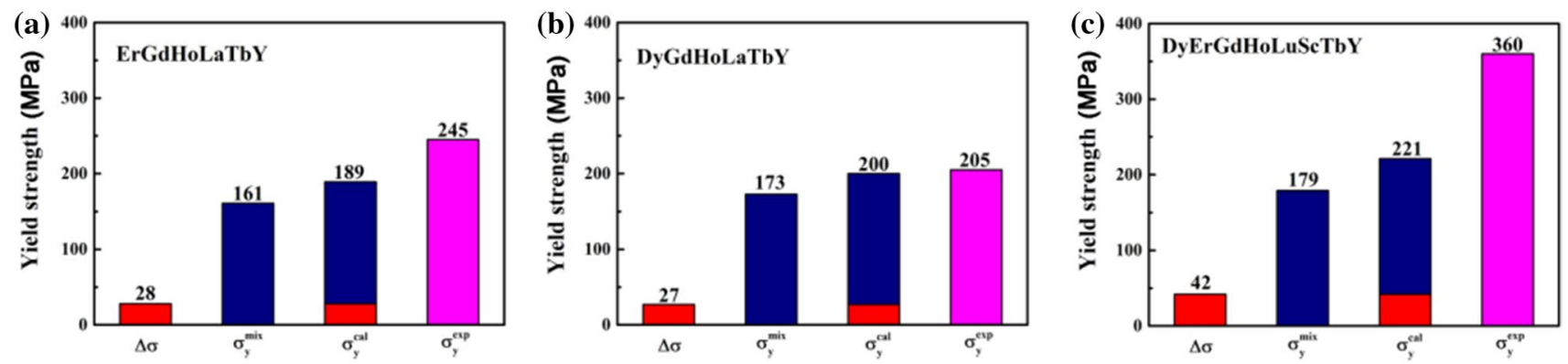

Fig. 7 Comparison in the yield stress between calculations and experiments [43] 
$\Delta S_{\mathrm{M}}=\int_{0}^{H}\left(\frac{\partial M}{\partial T}\right)_{H} \mathrm{~d} H$

The refrigerant capacity (RC) value, which is determined by the temperature range and the magnetic entropy, has been commonly used for comparing magnetocaloric materials. RC can be calculated by three different criteria: (a) $\left|\Delta S_{\mathrm{M}}^{\mathrm{pk}}\right| \times \delta T$; (b) $\int_{T 1}^{T 2} \Delta S_{\mathrm{M}} \mathrm{d} T$; and (c) the maximum value of $\Delta S_{\mathrm{M}} \times \delta T$ below the $\Delta S_{\mathrm{M}}(T)$ curve.

It has been accepted that the rare earth metal Gd has been the most typical magnetocaloric material in the room temperature. Gd exhibits ferromagnetic order from liquid helium temperature to room temperature, and its Curie temperature $T_{\mathrm{c}}=293 \mathrm{~K}$. The maximum magnetic enthalpy change of $\mathrm{Gd}$ under 0-2 $\mathrm{T}$ and 0-5 $\mathrm{T}$ magnetic field changes is about 5.0 and $9.7 \mathrm{~J} /(\mathrm{kgK})$. As a result, many Gd-based alloys also have great magnetocaloric effect.

Yuan et al. [49] studied the giant magnetocaloric effect of several rare-earth HEAs, including DyErGdHoTb, ErGdHoTb, DyErHoTb, and ErHoTb. They found that the quinary DyErGdHoTb alloy with the HCP structure exhibited a small magnetic hysteresis and possessed the largest $\mathrm{RC}$ reported to date (about $627 \mathrm{~J} \mathrm{~kg}^{-1}$ at the $5 \mathrm{~T}$ magnetic field), together with decent mechanical properties with the yield strength above $250 \mathrm{MPa}$ and plasticity larger than $20 \%$. A collection of magnetocalorific HEAs with different structures is summarized in Table 1. Chemical disorder in HEAs may cause sluggish magnetic phase transitions during cooling, resulting in an enhanced magnetocalorific effect, and among HEAs, Gd-containing multi-component alloys are the most outstanding ones in particular.

\subsection{Thermo-Stability}

Since metallic alloys for high-temperature load-bearing structures and thermal protection remain in high demand for the aerospace industry, there is a clear rationale for exploring alloys composed of constituents with high melting temperatures and high softening point. At present, it has been widely accepted that HEAs usually have excellent high-temperature properties and high melting temperatures, and can maintain their microstructure during high-temperature annealing. This is because the system entropy is high enough to decrease the Gibbs free energy, slow down the atomic diffusion, and stabilize the phase structure.

Some distinctive HEAs are promising for high-temperature applications and have the potential to replace Ni-base superalloys as the next-generation high-temperature materials, which nearly exclusively based on refractory metals, such as W, Mo, Nb, Ta, typically crystallizing in BCC structure. Due to the well-known high melting point of refractory elements, alloys manufactured from these elements seem to be very promising for applications at very high service temperatures. Outstanding values were reported for yield strength of $\mathrm{Nb}-\mathrm{Mo}-\mathrm{Ta}-\mathrm{W}$ and $\mathrm{V}-\mathrm{Nb}-\mathrm{Mo}-\mathrm{Ta}-\mathrm{W}$ alloys at temperatures of up to $1600{ }^{\circ} \mathrm{C}$. To reduce the strikingly high alloy density, some heavy refractory elements were substituted by lighter elements, such as $\mathrm{Zr}$ and Ti.

Recently, one novel HCP alloy system Ir-Mo-Rh-Ru-W with potentially excellent high thermo-stability is reported by Takeuchi et al. [56, 57]. They investigated that $\mathrm{Ir}_{26} \mathrm{Mo}_{20} \mathrm{Rh}_{22.5} \mathrm{Ru}_{20} \mathrm{~W}_{11.5}$ and $\mathrm{Ir}_{25.5} \mathrm{Mo}_{20} \mathrm{Rh}_{20} \mathrm{Ru}_{25} \mathrm{~W}_{9.5}$ alloys show single-phase HCP structure after annealing at $2373 \mathrm{~K}$ for $1 \mathrm{~h}$, and they exhibit a stable HCP phase for a wide range from 2500 to $1300 \mathrm{~K}$. Moreover, another refractory alloy $\mathrm{Ir}_{29.0678} \mathrm{Mo}_{15} \mathrm{Rh}_{29.0678} \mathrm{Ru}_{11.8644} \mathrm{~W}_{15}$ annealed at $1273 \mathrm{~K}$ for $200 \mathrm{~h}$ still maintains the single HCP structure. Table 2 exhibits the comparison of physical properties and hightemperature performances between these novel alloys and the reported refractory HEAs. The melting point and density are calculated using the equation $T_{\mathrm{m}}=\sum c_{i} T_{\mathrm{m} i}$ and $\rho=\frac{\sum c_{i} A_{i}}{\sum\left(c_{i} A_{i} / \rho_{i}\right)}$, respectively, where $c_{i}, A_{i}, \rho_{i}$, and $T_{\mathrm{m} i}$ are the atomic ratio, relative atomic mass, density, and melting point of the $i$ th component, respectively. It clearly shows that the newly developed HCP HEAs have similar melting point and high-temperature phase stability with other BCC refractory HEAs. Unfortunately, the density of these alloys is much higher than the existing refractory HEAs, and mechanical properties are not reported, so further researches are still needed.
Table 1 A collection of magnetocalorific HEAs with different structures in recent years

\begin{tabular}{llllll}
\hline Alloy & Structure & Applied field & $\left|\Delta S_{\mathrm{M}}\right|(\mathrm{J} / \mathrm{kg} / \mathrm{K})$ & $\mathrm{RC}(\mathrm{J} / \mathrm{kg})$ & References \\
\hline $\mathrm{FeCoNi}_{1.5} \mathrm{Cr}_{0.5} \mathrm{Al}$ & $\mathrm{BCC}$ & $70 \mathrm{kOe}$ & 0.674 & 242.6 & {$[50]$} \\
$\mathrm{Fe}_{26.7} \mathrm{Ni}_{26.7} \mathrm{Ga}_{15.6} \mathrm{Mn} 20 \mathrm{Si}_{11}$ & $\mathrm{BCC}$ & $2 \mathrm{~T}$ & 1.59 & 75.86 & {$[51]$} \\
$\mathrm{Fe}_{25} \mathrm{Co}_{25} \mathrm{Ni}_{25} \mathrm{Mo}_{5} \mathrm{P}_{10} \mathrm{~B}_{10}$ & $\mathrm{BMG}$ & $5 \mathrm{~T}$ & 1.88 & 310.2 & {$[52]$} \\
$\mathrm{Gd}_{20} \mathrm{Ho}_{20} \mathrm{Er}_{20} \mathrm{Al}_{20} \mathrm{Co}_{20}$ & $\mathrm{BMG}$ & $5 \mathrm{~T}$ & 10.2 & 625 & {$[53]$} \\
$\mathrm{Gd}_{20} \mathrm{~Tb}_{20} \mathrm{Dy}_{20} \mathrm{Al}_{20} \mathrm{Co}_{20}$ & $\mathrm{BMG}$ & $5 \mathrm{~T}$ & 9.43 & 632 & {$[54]$} \\
$\mathrm{Gd}_{25} \mathrm{Ho}_{25} \mathrm{Co}_{25} \mathrm{Al}_{25}$ & $\mathrm{BMG}$ & $5 \mathrm{~T}$ & 9.78 & 626 & {$[55]$} \\
$\mathrm{Dy}_{20} \mathrm{Er}_{20} \mathrm{Gd}_{20} \mathrm{Ho}_{20} \mathrm{~Tb}_{20}$ & $\mathrm{HCP}$ & $5 \mathrm{~T}$ & 8.6 & 627 & {$[49]$} \\
\hline
\end{tabular}


Table 2 Comparison of different refractory high-entropy alloys

\begin{tabular}{|c|c|c|c|c|c|}
\hline Alloy & $\begin{array}{l}\text { Melting } \\
\text { point }\left({ }^{\circ} \mathrm{C}\right)\end{array}$ & Density $\left(\mathrm{g} / \mathrm{cm}^{3}\right)$ & Structure & Phase stable condition & References \\
\hline $\mathrm{Ir}_{26} \mathrm{Mo}_{20} \mathrm{Rh}_{22.5} \mathrm{Ru}_{20} \mathrm{~W}_{11.5}$ & 2459 & 15.37 & $\mathrm{HCP}$ & Annealing at $2373 \mathrm{~K}$ for $1 \mathrm{~h}$ & {$[56]$} \\
\hline $\mathrm{Ir}_{25.5} \mathrm{Mo}_{20} \mathrm{Rh}_{20} \mathrm{Ru}_{25} \mathrm{~W}_{9.5}$ & 2444 & 15.18 & $\mathrm{HCP}$ & Annealing at $2373 \mathrm{~K}$ for $1 \mathrm{~h}$ & {$[56]$} \\
\hline $\mathrm{Ir}_{29.0678} \mathrm{Mo}_{15} \mathrm{Rh}_{29.0678} \mathrm{Ru}_{11.8644} \mathrm{~W}_{15}$ & 2463 & 16.07 & $\mathrm{HCP}$ & Annealing at $1273 \mathrm{~K}$ for $2000 \mathrm{~h}$ & {$[57]$} \\
\hline $\mathrm{Hf}_{25} \mathrm{Nb}_{25} \mathrm{Ti}_{25} \mathrm{Zr}_{25}$ & 2039 & 8.4 & $\mathrm{BCC}$ & Annealing at $1573 \mathrm{~K}$ for $6 \mathrm{~h}$ & {$[58]$} \\
\hline $\mathrm{Nb}_{25} \mathrm{Mo}_{25} \mathrm{Ta}_{25} \mathrm{~W}_{25}$ & 2904 & 13.64 & $\mathrm{BCC}$ & Annealing at $1673 \mathrm{~K}$ for $19 \mathrm{~h}$ & {$[11]$} \\
\hline $\mathrm{Nb}_{20} \mathrm{Mo}_{20} \mathrm{Ta}_{20} \mathrm{~W}_{20} \mathrm{~V}_{20}$ & 2673 & 12.36 & $\mathrm{BCC}$ & Annealing at $1673 \mathrm{~K}$ for $19 \mathrm{~h}$ & {$[11]$} \\
\hline $\mathrm{Ti}_{20} \mathrm{Zr}_{20} \mathrm{Hf}_{20} \mathrm{Nb}_{20} \mathrm{Ta}_{20}$ & 2231 & 9.94 & $\mathrm{BCC}$ & HIPing at $1473 \mathrm{~K}, 207 \mathrm{MPa}$ for $3 \mathrm{~h}$ & {$[14]$} \\
\hline $\mathrm{Mo}_{20} \mathrm{Nb}_{20} \mathrm{Ta}_{20} \mathrm{Ti}_{20} \mathrm{~V}_{20}$ & 2341 & 9.27 & $\mathrm{BCC}$ & Stable at $516-2162{ }^{\circ} \mathrm{C}$ by CALPHAD & [59] \\
\hline
\end{tabular}

The melting point and density are calculated using $T_{\mathrm{m}}=\sum c_{i} T_{\mathrm{m} i}$ and $\rho=\frac{\sum c_{i} A_{i}}{\sum\left(c_{i} A_{i} / \rho_{i}\right)}$, respectively, where $c_{i}, A_{i}, \rho_{i}$, and $T_{\mathrm{m} i}$ are the atomic ratio, relative atomic mass, density, and melting point of the $i$-th component, respectively

HIP hot isostatically press

\section{Discussion}

At present, researches on HCP HEAs mainly focus on the design of alloys with required structures by empirical formulas or simulations, but there are few studies on their mechanical properties, which may result from the intrinsic HCP crystal structures. There are few independent slip systems in the dense hexagonal structure, which therefore cause immense hardship to provide five independent strain components and satisfy the deformation coordination conditions. In addition, the degree of atomic closeness on each crystal plane varies with the axial ratio $c / a$. As a result, the deformation of the hexagonal crystal is much more complicated than that of FCC and BCC crystals. The axis ratio $c / a$, impurity atom concentration, test temperature, etc., all have a significant effect on the plastic deformation.

The atomic closeness changes with $c / a$ ratio, and then results in the change of slip plane and the amount of slip system. In general, when the axial ratio $c / a>1.63$, the slip is dominated by the basal plane $0001(<a>$ slip); when the axial ratio $c / a<1.63$, the basal plane is no longer the only close-packed one, other prismatic plane 1010 or the pyramidal plane 1011 also has a similar degree of closeness, even exceeding that of the basal surface, at which time prismatic and pyramidal sliding become possible. Table 3 shows the different slipping modes in the HCP alloy. Among all these slip, what's really rise the importance of the pyramidal slip system is that it can provide five independent strain components in the $\langle c+a\rangle$ slip. As a result, any HCP crystal exhibiting $\langle c+a\rangle$ slip fulfills the von Mises criterion and the homogeneous plastic deformation occur. In another word, the open of $\langle c+a\rangle$ slip will lead to a reduced singlecrystal plastic anisotropy, which is often blamed for HCP alloys' typically poor overall mechanical behavior. Now, there are two main ways by which non-basal $\langle c+a\rangle$ slip
Table 3 Different slipping modes in HCP alloys

\begin{tabular}{llll}
\hline Slip direction & Slip plane & Slip system & $\begin{array}{l}\text { Independent } \\
\text { slip number }\end{array}$ \\
\hline$a$ & Basal & $0001\langle 1 \overline{1} 0\rangle$ & 2 \\
& Prismatic & $1 \overline{1} 00\langle 11 \overline{2} 0\rangle$ & 2 \\
& Pyramidal & $1 \overline{1} 01\langle 11 \overline{2} 0\rangle$ & 4 \\
$c$ & Prismatic & hki0 $[0001]$ & \\
$c+a$ & Pyramidal & hkil $\langle 11 \overline{2} 3\rangle$ & 5 \\
\hline
\end{tabular}

dislocations can be generated (a) at/near surfaces and interfaces such as grain boundaries and incoherent twin boundaries, and (b) at heterogeneous sites in the grain interior such as the junction associated with $\langle a\rangle$ and $\langle c\rangle$ dislocations [60].

The development of HEAs provides a new way for $\langle c+a\rangle$ slip activation by adjusting alloying element content. Taking traditional $\mathrm{Mg}$ and Ti alloys as examples. Generally, the deformation of pure $\mathrm{Mg}$ with large $c / a$ ratio is dominated by only basal $\langle a\rangle$ slip, and its plasticity is severely limited [61]. Reduced axial ratio helps to obtain large plasticity, so in pure Ti alloys which have decreased cla ratio as 1.588 , the deformability can be enhanced relative to the Mg alloys, where only prismatic $\langle a\rangle$ slip occurs during deformation [62]. Figure 8 summarizes the changes in the $c / a$ ratio of several $\mathrm{Mg}-\mathrm{Li}, \mathrm{Mg}-\mathrm{Y}$, and $\mathrm{Ti}-\mathrm{Al}$ alloys [63-65]. It can be found that the increase in alloying elements shifts the axial ratio to the middle region, that is, $1.588<c / a<1.624$, and the study of alloy properties reveals that the shift of the axial ratio corresponds to the activation of $\langle c+a\rangle$ slip and the improvement of plasticity.

In the concept of entropy controlling, alloying element increasing in $\mathrm{Mg}-\mathrm{Li}, \mathrm{Mg}-\mathrm{Y}$, and $\mathrm{Ti}-\mathrm{Al}$ alloys corresponds to the increase in entropy value from low entropy 


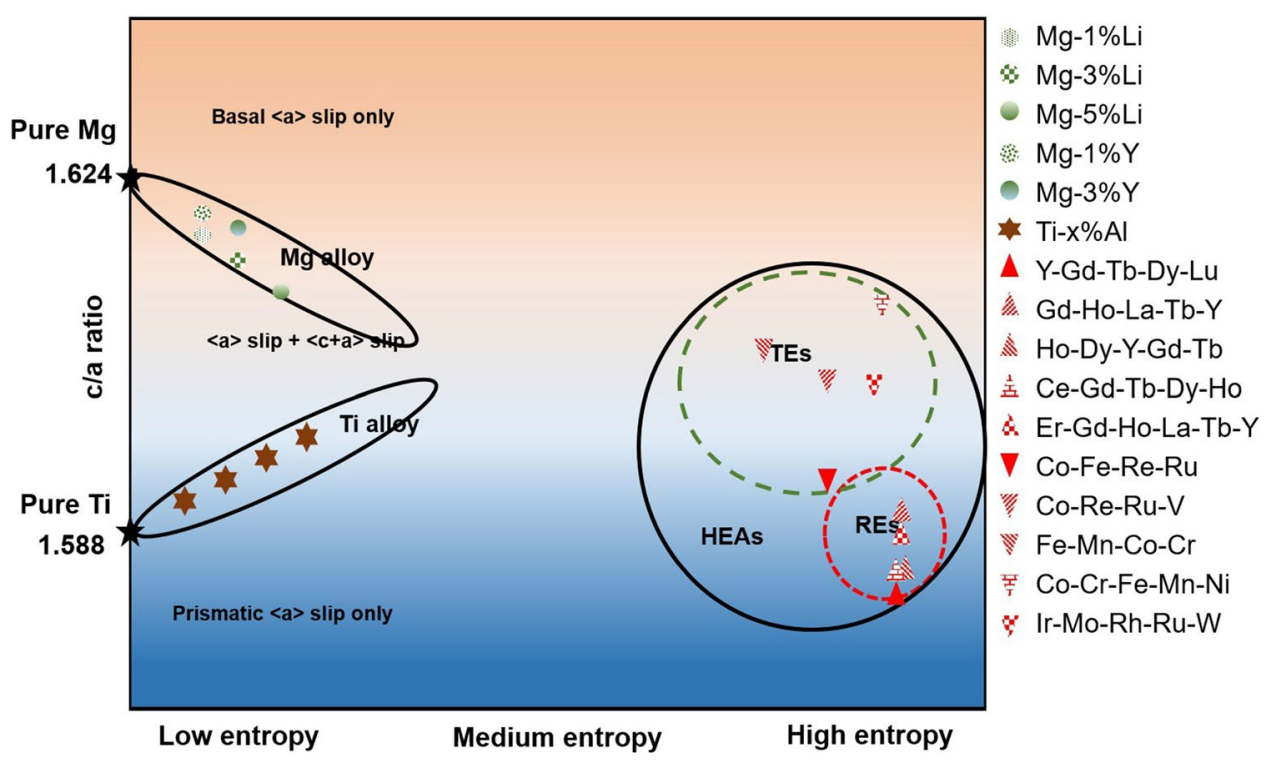

Fig. 8 Overview of the $c / a$ ratios of Mg alloys, Ti alloys and HEAs exhibiting HCP structure. $T E$ transitional elements, and $R E$ rare earth elements

to a range close to medium entropy. Therefore, it can be concluded that the entropy value has some influence on the open of $\langle c+a\rangle$ slip. Table 4 exhibits the currently developed single-phase HCP alloys and alloys with HCP structure as the main phase, and the cla ratio of these alloys are also added to the axial ratio slip mode diagram in Fig. 8. The $c / a$ value of transitional HCP HEAs falls exactly in the area where the $\langle c+a\rangle$ slip can be activated, such as $\mathrm{Fe}_{50} \mathrm{Mn}_{30} \mathrm{Cr}_{10} \mathrm{Co}_{10}$ and Co-Re-Ru-V, so they are more likely to have significant ductility in nature. When it turns to alloys composed of rare-earth elements, such as $\mathrm{Gd}_{20} \mathrm{Ho}_{20} \mathrm{La}_{20} \mathrm{~Tb}_{20} \mathrm{Y}_{20}$, the axial ratio $c / a$ reduces to the level

Table 4 Currently developed single-phase HCP alloys and alloys with HCP structure as the main phase

\begin{tabular}{|c|c|c|c|c|}
\hline Published year & Composition & Structure & $c / a$ & References \\
\hline 2013 & $\mathrm{Co}_{25} \mathrm{Os}_{25} \mathrm{Re}_{25} \mathrm{Ru}_{25}$ & HCP (predicted) & None & [16] \\
\hline 2014 & $\mathrm{Y}_{20} \mathrm{Gd}_{20} \mathrm{~Tb}_{20} \mathrm{Dy}_{20} \mathrm{Lu}_{20}$ & $\mathrm{HCP}+\mathrm{OMP}$ & 1.574 & {$[17]$} \\
\hline 2014 & $\mathrm{Gd}_{20} \mathrm{~Tb}_{20} \mathrm{Dy}_{20} \mathrm{Tm}_{20} \mathrm{Lu}_{20}$ & $\mathrm{HCP}+\mathrm{OMP}$ & 1.574 & {$[17]$} \\
\hline 2014 & $\mathrm{Ho}_{20} \mathrm{Dy}_{20} \mathrm{Y}_{20} \mathrm{Gd}_{20} \mathrm{~Tb}_{20}$ & $\mathrm{HCP}$ & 1.579 & {$[18,30]$} \\
\hline 2014 & $\mathrm{Al}_{20} \mathrm{Li}_{20} \mathrm{Mg}_{20} \mathrm{Sc}_{20} \mathrm{Ti}_{20}$ & HCP (annealing) & 1.588 & {$[37]$} \\
\hline 2015 & $\mathrm{Co}_{25} \mathrm{Fe}_{25} \mathrm{Re}_{25} \mathrm{Ru}_{25}$ & $\mathrm{HCP}$ & 1.581 & [29] \\
\hline 2015 & $\mathrm{Co}_{25} \mathrm{Re}_{25} \mathrm{Ru}_{25} \mathrm{~V}_{25}$ & $\mathrm{HCP}+\mathrm{OMP}$ & 1.606 & [29] \\
\hline 2016 & $\mathrm{Sc}_{16.67} \mathrm{Y}_{16.67} \mathrm{La}_{16.67} \mathrm{Ti}_{16.67} \mathrm{Zr}_{16.67} \mathrm{Hf}_{16.67}$ & Dual HCP & $1.583 / 1.575$ & {$[33]$} \\
\hline 2016 & $\mathrm{Gd}_{20} \mathrm{Ho}_{20} \mathrm{La}_{20} \mathrm{~Tb}_{20} \mathrm{Y}_{20}$ & $\mathrm{HCP}$ & 1.589 & {$[31]$} \\
\hline 2017 & $\mathrm{Al}_{15} \mathrm{Hf}_{25} \mathrm{Sc}_{10} \mathrm{Ti}_{25} \mathrm{Zr}_{25}$ & $\mathrm{HCP}+\mathrm{OMP}$ & 1.585 & {$[67]$} \\
\hline 2017 & $\mathrm{Ir}_{19} \mathrm{Os}_{22} \mathrm{Re}_{21} \mathrm{Rh}_{20} \mathrm{Ru}_{19}$ & $\mathrm{HCP}$ & 1.590 & {$[32]$} \\
\hline 2017 & $\mathrm{Gd}_{20} \mathrm{Dy}_{20} \mathrm{Er}_{20} \mathrm{Ho}_{20} \mathrm{~Tb}_{20}$ & $\mathrm{HCP}$ & 1.578 & [49] \\
\hline 2017 & $\mathrm{Co}_{20} \mathrm{Cr}_{20} \mathrm{Fe}_{20} \mathrm{Mn}_{20} \mathrm{Ni}_{20}$ & HCP (high pressure) & 1.620 & {$[34,35]$} \\
\hline 2017 & $\mathrm{Co}_{20} \mathrm{Cr}_{26} \mathrm{Fe}_{20} \mathrm{Mn}_{20} \mathrm{Ni}_{14}$ & HCP (high pressure torsion) & 1.620 & {$[36]$} \\
\hline 2017 & $\mathrm{Fe}_{50} \mathrm{Mn}_{30} \mathrm{Co}_{10} \mathrm{Cr}_{10}$ & $\mathrm{HCP}+\mathrm{FCC}$ & 1.616 & {$[38]$} \\
\hline 2018 & $\mathrm{Ce}_{20} \mathrm{Gd}_{20} \mathrm{~Tb}_{20} \mathrm{Dy}_{20} \mathrm{Ho}_{20}$ & $\mathrm{HCP}+\mathrm{OMP}$ & 1.588 & {$[68]$} \\
\hline 2018 & $\mathrm{Er}_{16.67} \mathrm{Gd}_{16.67} \mathrm{Ho}_{16.67} \mathrm{La}_{16.67} \mathrm{~Tb}_{16.67} \mathrm{Y}_{16.67}$ & $\mathrm{HCP}$ & 1.578 & {$[43]$} \\
\hline 2019 & $\mathrm{Ir}_{26} \mathrm{Mo}_{20} \mathrm{Rh}_{22.5} \mathrm{Ru}_{20} \mathrm{~W}_{11.5}$ & $\mathrm{HCP}$ & 1.601 & {$[56]$} \\
\hline 2019 & $\mathrm{Ir}_{25.5} \mathrm{Mo}_{20} \mathrm{Rh}_{20} \mathrm{Ru}_{25} \mathrm{~W}_{9.5}$ & $\mathrm{HCP}$ & 1.598 & {$[56]$} \\
\hline
\end{tabular}

$O M P$ other minor phase 


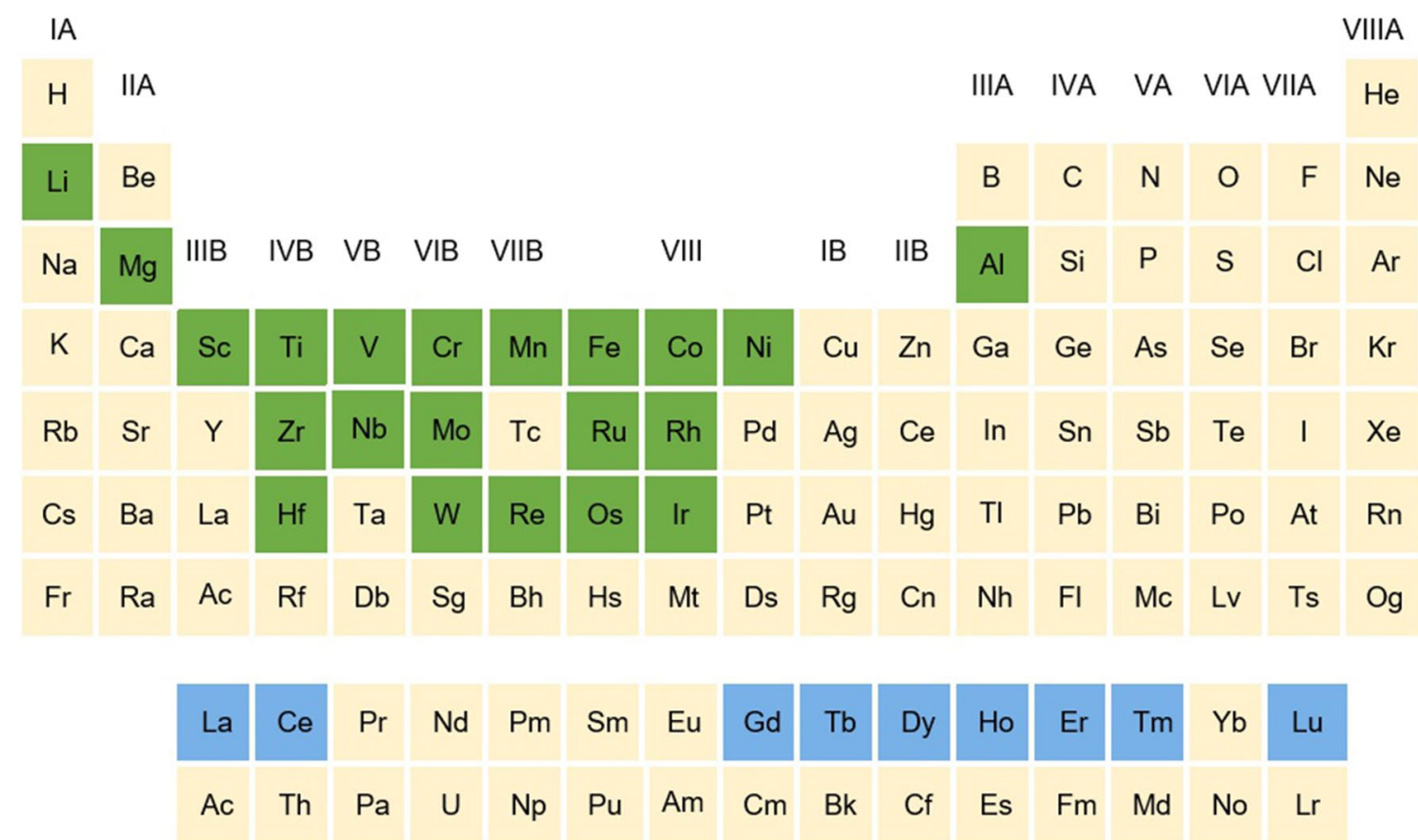

Fig. 9 Constituent elements used in the present HCP HEAs. The green areas exhibit the elements used in the first generation of HCP HEA, and the blue areas correspond to the second generation

of pure $\mathrm{Ti}$, placing themselves in the prismatic slip region. The ductility of these alloys therefore falls off to that similar with Ti alloys [31, 62], but they are still in decent value. In the dual-phase HEA Fe ${ }_{50} \mathrm{Mn}_{30} \mathrm{Cr}_{10} \mathrm{Co}_{10}$, Bu et al. observed $50 \%$ non-basal slip and double cross-slip in the HCP phase through in situ and postmortem observations, and proved that ductile HCP structure can be designed by increasing the alloying content and shifting the $c / a$ ratio into the middle regions, where the non-basal $\langle c+a\rangle$ dislocation slip is promoted [66].

Consequently, with the help of multi-alloying elements in HEAs, the shift in the cla ratio indeed leads to the activation of non-basal $\langle a\rangle$ and $\langle c+a\rangle$ slip, placing the HCP HEAs into a range where multiple deformation systems become active and contributing to the great ductility, especially in the alloys composed of transitional elements.

\section{Conclusion and Prospect}

HCP HEAs are based on the multi-principal-element concept combined with hexagonal crystal structure, and the study of them fills in the blanks of the total HEAs research, such as some fundamental understandings, processing methods, and properties. This article reviews the phase formation, physical properties, and mechanical properties of newly developed hexagonal HEAs. With the aid of four core effects of HEAs, hexagonal alloys have similar high-temperature properties, more special magnetic properties, and more complex mechanical properties, compared with traditional FCC and BCC HEAs. On the other hand, this field is still in its incipient stage, and there are still some problems and opportunities involved in the further research:

(1) The first generation of HCP HEAs mainly consists of rare-earth elements, and these alloys are mainly prepared using arc melting method. Figure 9 shows the constituent elements using in present HCP HEAs, and the green areas exhibit the elements used in the first generation. Then, along with the expansion of HEA definitions changing from equi-molar to non-equimolar multi-phase solid solution alloys, the second generation rises, and they are composed of transitional or lightweight elements [32, 37], just as the blue areas shown in Fig. 9. Diversified preparation methods have also been employed, such as mechanical alloying, thermal decomposition, and gas atomization. A variety of dual-phase and multi-phase HEAs containing HCP phases have also been developed to help improve the overall performance of the alloys. However, there are still some similar elements located in the same family or the same period in the phase diagram not been used, such as Pr, Md, and Pm in the Lanthanide and Ta and $\mathrm{Te}$ in the transitional family. As a result, based on these unused vacancy elements, more novel hexagonal alloys may also be developed. 
(2) Compared with experimental exploring, the alloy designing, based on the properties calculated by the DFT method and the multi-component phase diagrams assessed by CALPHAD, is an effective way to save time and reduce the cost [69-71]. However, the multiple elements and complex microstructures make the computation much more complex. Furthermore, there exists a difference between simulation results and experiment. Therefore, based on experimental verification, a more efficient HEA database needs to be built and improved.

(3) There is a great opportunity for HEAs to overcome the bottlenecks of conventional alloys. As for HCP HEAs, further studies still needed, while they are supposed to provide broad potential use in the high-temperature, magnetic, and superconductivity field. The high-temperature mechanical and oxidation resistance of the alloys need to be optimized. In order to further decrease the density, the light elements, such as $\mathrm{Al}$ $\left(\rho=2.7 \mathrm{~g} / \mathrm{cm}^{3}\right), \mathrm{V}\left(\rho=6.11 \mathrm{~g} / \mathrm{cm}^{3}\right), \operatorname{Zr}(\rho=6.51 \mathrm{~g} /$ $\left.\mathrm{cm}^{3}\right), \mathrm{Cr}\left(\rho=7.14 \mathrm{~g} / \mathrm{cm}^{3}\right)$, and $\operatorname{Ti}\left(\rho=4.51 \mathrm{~g} / \mathrm{cm}^{3}\right)$, can be employed. Secondly, since the size of different elements in HEAs can be very different in some cases, the slip modes can be adjusted and enough slip system can be activated, contributing to the enhanced ductility and paving the way to develop high-performance alloys. Thirdly, the superconductivity of HCP binaries $\mathrm{Re}-\mathrm{Os}, \mathrm{Re}-\mathrm{Ru}, \mathrm{Ru}-\mathrm{Os}$, and $\mathrm{Re}-\mathrm{W}$ has been studied [72], and HCP HEAs through substitutional of these similar elements have also been investigated. It is to be expected that novel superconductivity will be reported, after combining the four special effects of HEAs. Last, based on their small magnetic hysteresis and large RC, these special hexagonal HEAs are conducive to the development of environmentally friendly magneticrefrigerant materials with excellent comprehensive properties.

Acknowledgements Yong Zhang would like to thank the financial support from the National Natural Science Foundation of China (No 51671020) and the Fundamental Research Funds for the Central Universities (No. FRF-MP-19-013)

\section{References}

[1] J.W. Yeh, S.K. Chen, S.J. Lin, J.Y. Gan, T.S. Chin, T.T. Shun, C.H. Tsau, S.Y. Chang, Adv. Eng. Mater. 6, 299 (2004)

[2] S.F. Zhao, Y. Shao, X. Liu, N. Chen, H.Y. Ding, K.F. Yao, Mater. Des. 87, 625 (2015)

[3] H.Y. Ding, Y. Shao, P. Gong, J.F. Li, K.F. Yao, Mater. Lett. 125, $151(2014)$

[4] M.A. Hemphill, T. Yuan, G.Y. Wang, J.W. Yeh, C.W. Tsai, A. Chuang, P.K. Liaw, Acta Mater. 60, 5723 (2012)
[5] S. Jiang, H. Wang, Y. Wu, X. Liu, H. Chen, M. Yao, B. Gault, D. Ponge, D. Raabe, A. Hirata, M. Chen, Y. Wang, Z. Lu, Nature 544, 460 (2017)

[6] I. Basu, V. Ocelik, J.T.M. De Hosson, Acta Mater. 150, 104 (2018)

[7] D. Li, C. Li, T. Feng, Y. Zhang, G. Sha, J.J. Lewandowski, P.K. Liaw, Y. Zhang, Acta Mater. 123, 285 (2017)

[8] J. Liu, X. Guo, Q. Lin, Z. He, X. An, L. Li, P.K. Liaw, X. Liao, L. Yu, J. Lin, L. Xie, J. Ren, Y. Zhang, Sci. China Mater. 62, 853 (2019)

[9] Z. Zhang, M. Mao, J. Wang, B. Gludovatz, Z. Zhang, S.X. Mao, E.P. George, Q. Yu, R.O. Ritchie, Nat. Commun. 6, 10143 (2015)

[10] Y. Zhang, S.G. Ma, J.W. Qiao, Metall. Mater. Trans. A 43, 2625 (2011)

[11] O.N. Senkov, G.B. Wilks, D.B. Miracle, C.P. Chuang, P.K. Liaw, Intermetallics 18, 1758 (2010)

[12] O.N. Senkov, G.B. Wilks, J.M. Scott, D.B. Miracle, Intermetallics 19, 698 (2011)

[13] W. Zhang, P. Liaw, Y. Zhang, Entropy 20, 951 (2018)

[14] O.N. Senkov, J.M. Scott, S.V. Senkova, D.B. Miracle, C.F. Woodward, J. Alloys Compd. 509, 6043 (2011)

[15] Y.L. Chen, C.W. Tsai, C.C. Juan, M.H. Chuang, J.W. Yeh, T.S. Chin, S.K. Chen, J. Alloys Compd. 506, 210 (2010)

[16] M. Gao, D. Alman, Entropy 15, 4504 (2013)

[17] A. Takeuchi, K. Amiya, T. Wada, K. Yubuta, W. Zhang, JOM 66, $1984(2014)$

[18] M. Feuerbacher, M. Heidelmann, C. Thomas, Mater. Res. Lett. 3, 1 (2014)

[19] Y. Zhang, Y.J. Zhou, J.P. Lin, G.L. Chen, P.K. Liaw, Adv. Eng Mater. 10, 534 (2008)

[20] Y. Zhang, T.T. Zuo, Z. Tang, M.C. Gao, K.A. Dahmen, P.K. Liaw, Z.P. Lu, Prog. Mater. Sci. 61, 1 (2014)

[21] A. Takeuchi, A. Inoue, Mater. Trans. 46, 2817 (2005)

[22] X. Yang, Y. Zhang, Mater. Chem. Phys. 132, 233 (2012)

[23] S. Guo, C. Ng, J. Lu, C.T. Liu, J. Appl. Phys. 109, 103505 (2011)

[24] Y.F. Ye, Q. Wang, J. Lu, C.T. Liu, Y. Yang, Mater. Today 19, 349 (2016)

[25] Y.F. Ye, Q. Wang, J. Lu, C.T. Liu, Y. Yang, Scr. Mater. 104, 53 (2015)

[26] Y.F. Ye, Q. Wang, Y.L. Zhao, Q.F. He, J. Lu, Y. Yang, J. Alloys Compd. 681, 167 (2016)

[27] Y.F. Ye, C.T. Liu, Y. Yang, Acta Mater. 94, 152 (2015)

[28] Y.F. Ye, X.D. Liu, S. Wang, C.T. Liu, Y. Yang, Intermetallics 78, $30(2016)$

[29] M.C. Gao, B. Zhang, S.M. Guo, J.W. Qiao, J.A. Hawk, Metall. Mater. Trans. A 47, 3322 (2015)

[30] J. Lužnik, P. Koželj, S. Vrtnik, A. Jelen, Z. Jagličić, A. Meden, M. Feuerbacher, J. Dolinšek, Phys. Rev. B 92, 224201 (2015)

[31] Y.J. Zhao, J.W. Qiao, S.G. Ma, M.C. Gao, H.J. Yang, M.W. Chen, Y. Zhang, Mater. Des. 96, 10 (2016)

[32] K.V. Yusenko, S. Riva, P.A. Carvalho, M.V. Yusenko, S. Arnaboldi, A.S. Sukhikh, M. Hanfland, S.A. Gromilov, Scr. Mater. 138, 22 (2017)

[33] A. Takeuchi, K. Amiya, T. Wada, K. Yubuta, Intermetallics 69, 103 (2016)

[34] F. Zhang, Y. Wu, H. Lou, Z. Zeng, V.B. Prakapenka, E. Greenberg, Y. Ren, J. Yan, J.S. Okasinski, X. Liu, Y. Liu, Q. Zeng, Z. Lu, Nat. Commun. 8, 15687 (2017)

[35] C.L. Tracy, S. Park, D.R. Rittman, S.J. Zinkle, H. Bei, M. Lang, R.C. Ewing, W.L. Mao, Nat. Commun. 8, 15634 (2017)

[36] J. Moon, Y. Qi, E. Tabachnikova, Y. Estrin, W.M. Choi, S.H. Joo, B.J. Lee, A. Podolskiy, M. Tikhonovsky, H.S. Kim, Mater. Lett. 202, 86 (2017)

[37] K.M. Youssef, A.J. Zaddach, C. Niu, D.L. Irving, C.C. Koch, Mater. Res. Lett. 3, 95 (2014)

[38] Z. Li, C.C. Tasan, K.G. Pradeep, D. Raabe, Acta Mater. 131, 323 (2017) 
[39] C.H. Tsau, Y.H. Chang, Entropy 15, 5012 (2013)

[40] C.H. Tsau, Mater. Sci. Eng. A 501, 81 (2009)

[41] T.T. Shun, C.H. Hung, C.F. Lee, J. Alloys Compd. 495, 55 (2010)

[42] T.T. Shun, C.H. Hung, C.F. Lee, J. Alloys Compd. 493, 105 (2010)

[43] J.W. Qiao, M.L. Bao, Y.J. Zhao, H.J. Yang, Y.C. Wu, Y. Zhang, J.A. Hawk, M.C. Gao, J. Appl. Phys. 124, 195101 (2018)

[44] T. Zuo, M.C. Gao, L. Ouyang, X. Yang, Y. Cheng, R. Feng, S. Chen, P.K. Liaw, J.A. Hawk, Y. Zhang, Acta Mater. 130, 10 (2017)

[45] T. Zuo, M. Zhang, P.K. Liaw, Y. Zhang, Intermetallics 100, 1 (2018)

[46] R. Li, H. Hao, Y. Zhao, Y. Zhang, Metals 7, 76 (2017)

[47] Y. Li, W. Zhang, T. Qi, J. Alloys Compd. 693, 25 (2017)

[48] Y. Zhang, M. Zhang, D. Li, T. Zuo, K. Zhou, M. Gao, B. Sun, T. Shen, Metals 9, 382 (2019)

[49] Y. Yuan, Y. Wu, X. Tong, H. Zhang, H. Wang, X.J. Liu, L. Ma, H.L. Suo, Z.P. Lu, Acta Mater. 125, 481 (2017)

[50] S.M. Na, P.K. Lambert, H. Kim, J. Paglione, N.J. Jones, AIP Adv. 9, 035010 (2019)

[51] K. Sarlar, A. Tekgül, I. Kucuk, Curr. Appl. Phys. 20, 18 (2020)

[52] K. Wu, C. Liu, Q. Li, J. Huo, M. Li, C. Chang, Y. Sun, J. Magn. Magn. Mater. 489, 165404 (2019)

[53] W. Sheng, J.Q. Wang, G. Wang, J. Huo, X. Wang, R.W. Li, Intermetallics 96, 79 (2018)

[54] J. Huo, L. Huo, H. Men, X. Wang, A. Inoue, J. Wang, C. Chang, R.W. Li, Intermetallics 58, 31 (2015)

[55] L. Xue, L. Shao, Q. Luo, B. Shen, J. Alloy. Compd. 790, 633 (2019)

[56] A. Takeuchi, T. Wada, H. Kato, Mater. Trans. 60, 1666 (2019)
[57] A. Takeuchi, T. Wada, H. Kato, Mater. Trans. 60, 2267 (2019)

[58] Y.D. Wu, Y.H. Cai, T. Wang, J.J. Si, J. Zhu, Y.D. Wang, X.D. Hui, Mater. Lett. 130, 277 (2014)

[59] H.W. Yao, J.W. Qiao, J.A. Hawk, H.F. Zhou, M.W. Chen, M.C. Gao, J. Alloy. Compd. 696, 1139 (2017)

[60] M. Yoo, S. Agnew, J. Morris, K. Ho, Mater. Sci. Eng. A 319, 87 (2001)

[61] Z. Wu, R. Ahmad, B. Yin, S. Sandlöbes, W. Curtin, Science 359, 447 (2018)

[62] X.N. Mu, H.N. Cai, H.M. Zhang, Q.B. Fan, Z.H. Zhang, Y. Wu, Y.X. Ge, D.D. Wang, Mater. Des. 140, 431 (2018)

[63] S. Agnew, M. Yoo, C. Tome, Acta Mater. 49, 4277 (2001)

[64] J.S. Park, Y.W. Chang, Adv. Mater. Res. 26, 95 (2007)

[65] H.R. Ogden, D.J. Maykuth, W.L. Finlay, R.I. Jaffee, JOM 3, 1150 (1951)

[66] Y. Bu, Z. Li, J. Liu, H. Wang, D. Raabe, W. Yang, Phys. Rev. Lett. 122, 075502 (2019)

[67] L. Rogal, P. Bobrowski, F. Kormann, S. Divinski, F. Stein, B. Grabowski, Sci. Rep. 7, 2209 (2017)

[68] S. Vrtnik, J. Lužnik, P. Koželj, A. Jelen, J. Luzar, Z. Jagličić, A. Meden, M. Feuerbacher, J. Dolinšek, J. Alloy. Compd. 742, 877 (2018)

[69] Y. Ikeda, B. Grabowski, F. Koermann, Mater. Charact. 147, 464 (2019)

[70] F.X. Zhang, S. Zhao, K. Jin, H. Xue, G. Velisa, H. Bei, R. Huang, J.Y.P. Ko, D.C. Pagan, J.C. Neuefeind, W.J. Weber, Y. Zhang, Phys. Rev. Lett. 118, 205501 (2017)

[71] F. Tian, H. Zhao, Y. Wang, N. Chen, Scr. Mater. 166, 164 (2019)

[72] C.W. Chu, W.L. McMillan, H.L. Luo, Phys. Rev. B 3, 3757 (1971) 